Emilio Figueroa Reinoso

\title{
La sociedad unipersonal
}

La importancia de su regulación en el derecho societario

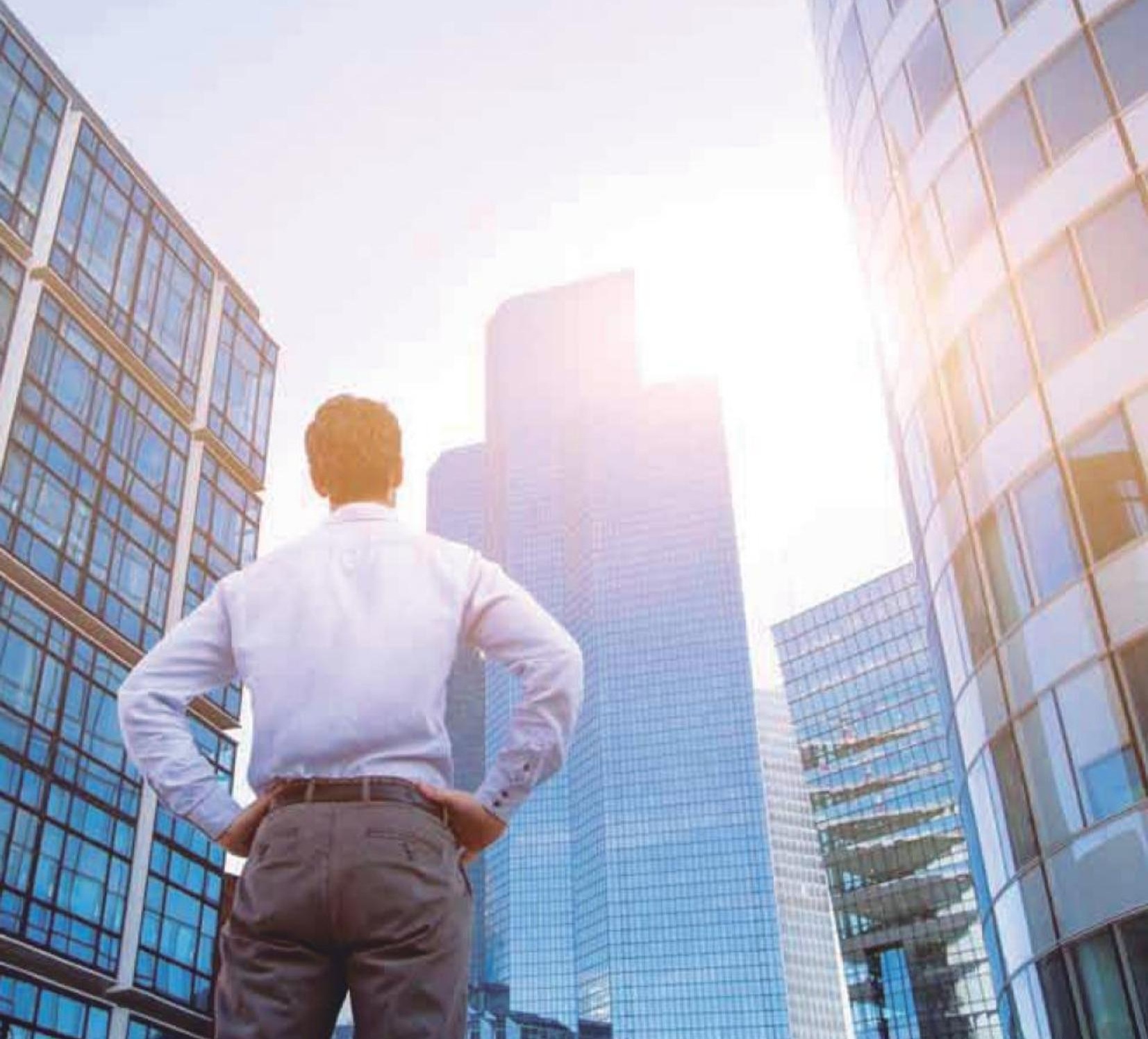


Emilio FigueroA R E I N O O

La sociedad unipersonal

La importancia de su regulación en el derecho societario

Lima, octubre de 2016

Universidad Peruana de Ciencias Aplicadas 
(C) Universidad Peruana de Ciencias Aplicadas (UPC)

Primera publicación: octubre de 2016

Impreso en el Perú - Printed in Peru

$\begin{array}{ll}\text { Autor: } & \text { Emilio Figueroa } \\ \text { Edición: } & \text { Diana Félix } \\ \text { Corrección de estilo: } & \text { Luigi Battistolo } \\ \text { Diseño de cubierta: } & \text { Christian Castañeda } \\ \text { Diagramación: } & \text { Diana Patrón Miñán }\end{array}$

Editor del proyecto editorial

Universidad Peruana de Ciencias Aplicadas S. A.C.

Av. Alonso de Molina 1611, Lima 33 (Perú)

Teléf: 313-3333

www.upc.edu.pe

Primera edición: octubre de 2016

Tiraje: 800 ejemplares

Este libro se terminó de imprimir en el mes de octubre de 2016, en los talleres gráficos de DOSMASUNO S.A.C., Jr. Chavez Tueros №1224 Chacra Rios Sur, Lima - Perú.

\section{BIBLIOTECA NACIONAL DEL PERÚ \\ Centro Bibliográfico Nacional}

347.51 Figueroa Reinoso, Emilio

F49 La sociedad unipersonal : la importancia de su regulación en el derecho societario / Emilio Figueroa Reinoso.-- 1a ed.-- Lima : Universidad Peruana de Ciencias Aplicadas, 2016 (Lima : Dosmasnuno).

279 p. : il. ; $24 \mathrm{~cm}$

Bibliografía: p. 161-170.

D.L. 2016-12362

ISBN 978-612-318-070-6

1. Corporaciones unipersonales - Aspectos legales - Perú 2. Sociedades comerciales - Aspectos legales - Perú 3. Empresas (Derecho comercial) - Perú 4. Derecho comercial - Perú - Interpretación y aplicación I. Universidad Peruana de Ciencias Aplicadas (Lima) II. Título

BNP: 2016-656

Hecho el Depósito Legal en la Biblioteca Nacional del Perú nro. 2016-12362

Registro de Proyecto Editorial en la Biblioteca Nacional del Perú nro. 31501401601000

Todos los derechos reservados. Esta publicación no puede ser reproducida, ni en todo ni en parte, ni registrada en o transmitida por un sistema de recuperación de información, en ninguna forma ni por ningún medio, sea mecánico, fotoquímico, electrónico, magnético, electroóptico, por fotocopia o cualquier otro, sin el permiso previo, por escrito, de la editorial.

El contenido de este libro es responsabilidad del autor y no refleja necesariamente la opinión de los editores. 


\section{Contenido}

$\begin{array}{lr}\text { Agradecimiento } & 9\end{array}$

$\begin{array}{lr}\text { Prólogo } & 11\end{array}$

$\begin{array}{ll}\text { Introducción } & 13\end{array}$

Capítulo 1. Análisis de la problemática en nuestra realidad societaria peruana 19

$\begin{array}{ll}1.1 \text { Analizando el problema caso por caso } & 19\end{array}$

1.2 Fundamento constitucional de la unipersonalidad societaria 26

Capítulo 2. Análisis y desarrollo doctrinario del origen de la unipersonalidad societaria $\quad 31$

2.1 Aspectos doctrinales de la constitución de sociedades unipersonales y $\begin{array}{ll}\text { pluripersonales } & 31\end{array}$

2.2 Sociedad unipersonal en la doctrina del derecho societario. Análisis de las diferentes teorías jurídicas. La tesis organicista o institucionalista como fundamento básico de la sociedad unipersonal $\quad 42$

2.3 Sobre la exigencia (innecesaria) de la pluralidad de socios para la creación de sociedades en la normatividad peruana $\quad 50$

2.4 Sobre las sociedades unipersonales y las sociedades pluripersonales 53

2.5 La sociedad unipersonal 66

Capítulo 3. Unipersonalidad societaria en la normatividad peruana $\quad 73$

3.1 Las sociedades unipersonales (existentes y vigentes) en nuestra $\begin{array}{ll}\text { normatividad societaria peruana } & 73\end{array}$

3.2 La sociedad unipersonal en reemplazo de la EIRL. Análisis general 84 
3.3 Legislación comparada sobre la unipersonalidad societaria. Colombia, Inglaterra, Alemania, Francia y Estados Unidos

3.4 Análisis de la Directiva 89/667/CEE de la Comunidad Económica Europea del 21 de diciembre de 1989 y de la Directiva de la Comunidad Europea 2009/102/CE del Parlamento Europeo del 16 de setiembre de 2009 en materia de sociedades relativa a las sociedades de responsabilidad limitada de socio único

3.5 Comentarios al Proyecto de Directiva del Parlamento Europeo y del Consejo sobre las societas unius personae del 9 de abril de 2014

\section{Capítulo 4. La sociedad unipersonal}

4.1 Antecedentes. Normas constitucionales. Libertad de contratar y libertad económica

4.2 La sociedad unipersonal como nuevo sujeto jurídico

4.3 Constitución de una sociedad unipersonal

4.4 Condiciones de los bienes en la sociedad unipersonal

4.5 Organización de la sociedad unipersonal

4.6 De la responsabilidad del socio unipersonal

4.7 Contratación del socio unipersonal. Relaciones jurídicas internas y externas

4.8 De las relaciones con los acreedores sociales

4.9 Publicidad de la sociedad unipersonal ante terceros

4.10 Fin de la sociedad unipersonal

4.11 De las transmisiones intervivos y/o mortis causa, copropiedad, usufructo, prenda, y medidas cautelares de las participaciones o acciones del socio único 142 
Los sueños no sirvieron para verlos solos en una cama, sino para que los vean los demás; porque ciencia que no se ve es ciencia que no existe. Persevera, persevera, nadie gana sin haber luchado, sin haber sufrido y sin haber llorado; y después, cuando lo logres, verás que no era tan complicado. 


\section{Agradecimiento}

A Dios, a mis madres en el cielo, a mi madre Clara en la Tierra y a mi único amor, Sandra. 


\section{Prólogo}

La unipersonalidad societaria es un tema que desde hace varios años ha llamado nuestra atención, por lo que hemos difundido ampliamente nuestras ideas al respecto, con gran receptividad en diversos medios jurídicos peruanos y extranjeros. Nuestro primer acercamiento se produjo en julio de 2002, cuando se publicó el artículo «La legislación societaria en el Perú (reflexiones jurídicas)». Con mayor atención nos avocamos a la unipersonalidad societaria cuando, en julio de 2004, apareció el trabajo «La sociedad de un solo socio».

Posteriormente abordamos en forma crítica el tratamiento ofrecido por nuestra Ley General de Sociedades a la pérdida de la pluralidad de socios, en el artículo «¿Disolver o no disolver?: he ahí el dilema», publicado en mayo de 2005. No podíamos eludir este tópico en el balance que efectuamos de la normatividad societaria peruana, el cual vio la luz en junio de 2005 con el ensayo «Lo errado, lo inconcluso y lo imprevisto en la Ley General de Sociedades». Finalmente, como un nuevo esquema de organización corporativa, ha sido desarrollado en los artículos «Las nuevas alternativas societarias en la legislación extranjera», de abril de 2008, y «La sociedad unipersonal», así como en el libro Derecho Societario. Un nuevo enfoque jurídico de los temas societarios, los dos últimos publicados en junio de 2009.

Puede advertirse entonces que nos adelantamos por varios años a la problemática que ahora se aborda magistralmente y de manera integral en esta obra, $L a$ sociedad unipersonal, del joven abogado Emilio Figueroa, egresado de las aulas de la Facultad de Derecho de la Universidad de San Martín de Porres. La referida obra empieza por el «Análisis de la problemática en nuestra realidad societaria peruana» (capítulo 1), continúa con el «Análisis y desarrollo doctrinario del origen de la unipersonalidad societaria» (capítulo 2) y la «Unipersonalidad societaria en la normatividad peruana» (capítulo 3), y finaliza con «La sociedad unipersonal» (capítulo 4).

Respecto a la unipersonalidad societaria sobreviniente, el Código de Comercio venezolano la admite en su artículo 341, cuando prescribe que «la sociedad anónima y la sociedad de responsabilidad limitada no se disuelven por haber adquirido uno de los socios todas las acciones o cuotas de la sociedad». Por su parte, el Código de Comer- 
cio de Uruguay fue reformado para permitir que, «luego de constituida la sociedad, la totalidad de las acciones pudieran concentrarse en manos de un solo accionista». En el Perú no es posible la subsistencia de sociedades con un solo socio, porque el efecto jurídico que se le atribuye a la pérdida de la pluralidad de socios es la disolución de la sociedad si es que no recompone aquella pluralidad en el plazo de seis meses. Empero, aquí existe una antinomia, que en las diversas publicaciones mencionadas ha sido analizada al detalle.

Estamos, pues, ante un interesante tema jurídico que merece el estudio, el análisis y la reflexión, como bien se hace en esta obra que tenemos el privilegio de prologar.

Daniel Echaiz Moreno

Socio fundador de Echaiz Abogados y Presidente de la Comisión Consultiva de Derecho Financiero y Bancario del Colegio de Abogados de Lima 


\section{Introducción}

¿Por qué no?

Cuentan que una vez un profesor de filosofía hizo que sus alumnos aprendieran todas las teorías filosóficas para el examen final. Llegado el día, les entregó un cuadernillo de diez hojas con el que podrían desarrollar la prueba durante las dos horas que duraba. Cuando los alumnos abrieron el cuadernillo, solo había una pregunta: «¿Por qué?».

Así, muchos de ellos comenzaron a escribir profusamente respondiendo lo solicitado, basándose en Spencer, Nietzsche, Platón, Sócrates y Sartre, explayándose extensamente en todas las páginas del cuadernillo. pero uno de ellos entregó el cuadernillo con solo una respuesta: «¿Por qué no?». Ese alumno fue el único que aprobó el examen.

Al empezar con esta investigación nunca pensamos que nos «meteríamos en una camisa de once varas» al proponer la posibilidad de una unipersonalidad societaria, o la llamada sociedad unipersonal, en el Perú. Ese «¿por qué?» y el «¿por qué no?»se metieron en la cabeza del autor y se dieron la tarea de desarrollar ampliamente el tema de la unipersonalidad societaria, sobre todo la posibilidad de regularla para permitirla. Esta figura, que más propiamente pareciera una opción, no es nueva en el mundo jurídico: es una propuesta innovadora en lo referido a la forma en la cual se pueden realizar actividades empresariales en solitario, sin tener que pasar por el sacrosanto camino de la agrupación, como única base y sustento para crear una sociedad. Y a pesar de que la ley peruana dice que no, en realidad existe desde hace muchísimo tiempo.

Es desde allí que comenzaron a surgir las preguntas: cuando pensamos en una sociedad, ¿siempre se trata, obligatoriamente, de la unión de dos personas? ¿No es acaso la sociedad una persona diferente de sus miembros creadores o socios? ¿La única forma de constituir una sociedad es un contrato? ¿Es obligatoria la permanencia de dos miembros para que una sociedad siga funcionando? ¿Es correcto que la ley disuelva de pleno derecho a una sociedad legalmente constituida con valor en el mercado, con cartera de clientes, proveedores, obligaciones y trabajadores solo porque uno de los socios ya no está y el otro queda solo? ¿Es el concepto etimológico «sociedad» más importante que el concepto jurídico «sociedad»? 
Y la pregunta más conflictiva y contradictoria: ¿es posible la existencia de una sociedad nacida o constituida por una sola persona?

Consideramos que la búsqueda de nuevas formas y nuevas ideas es la base fundamental para el desarrollo del derecho, así como de toda educación y formación humana. Pensar que determinado concepto es el único y que solo se puede hacer algo de una forma establecida no solo es limitante, sino mediocrizante. Es necesario aventurarnos y ver más allá.

Así, la presente investigación, que tuvo su inicio en el tema de tesis de magíster del autor, tiene como fin describir en detalle y fijar posición respecto de la unipersonalidad societaria, así como de la importancia de permitir la existencia y regulación de la sociedad unipersonal en el Perú en forma total y no para un grupo privilegiado. El objetivo principal en este libro es poder ampliar y analizar el concepto jurídico de sociedad y no quedarnos únicamente con el concepto etimológico, lingüístico o gramatical de que una sociedad es la unión de dos personas. No estamos enfrentándonos a una lucha en el aspecto literal del término, sino a la conceptualización de la figura de sociedad en la visión jurídica, desde el punto de vista del derecho corporativo.

De ese modo, en la opinión particular del autor luego de haber revisado diversa doctrina internacional, la sociedad no nace necesariamente de un contrato, sino que también puede hacerlo de la voluntad o declaración humana, de la creación única de una persona sin que sea considerado ilógico o un imposible jurídico. Si uno de los principios societarios es que la sociedad es una persona jurídica creada e independiente de los miembros que tiene existencia propia, ¿por qué debemos seguir creyendo que sin uno de ellos la sociedad ya no debe existir?

¿Es que acaso la soledad de un socio dentro de una sociedad, cuando nació de varios, hace que ella deba desaparecer? La respuesta es NO.

Y entonces...

El sistema societario en el ámbito comercial es una de las ramas del derecho en constante cambio y evolución; por lo tanto, no puede ser ajeno a situaciones que muestran realidades que deben ser reguladas. Una de ellas, y la que es motivo de este libro, es la opción de realizar en forma única (sin necesidad de otras personas o socios) actividades comerciales, gozando de los beneficios con los que cuentan las sociedades anónimas, principalmente la responsabilidad limitada.

En nuestro medio, la única forma de realizar actividad unipersonal es bajo los alcances del D. L. 21621, Ley de la EIRL (empresa individual de responsabilidad limitada), promulgada el 15 de setiembre de 1976. 
Enfrentémoslo: han pasado casi 40 años y la norma sigue igual. Ello no significa que sea buena, ni tampoco que sea mala. Lo que significa es que no hay nada más que hacerle, nada que hacer para mejorarla. Pero... ¿acaso los tiempos no han cambiado? ¿Acaso no es evidente el desarrollo societario mundial con relación a la globalización? La EIRL ha sido un interesante tubo de ensayo para la persona que empieza en la actividad comercial, pero no es la forma más eficiente, y no necesitamos probarlo, ya que es evidente. En el ámbito internacional se están buscando nuevas formas de promover el tráfico y generar elementos que propicien la reducción de los costos de transacción. Un modo de hacerlo es la posibilidad de la unipersonalidad societaria.

Cuando nos referimos a la sociedad como figura jurídica, notamos que ha evolucionado exponencialmente, que es materia de muchos análisis doctrinarios y de diversos estudios. Una prueba de que la sociedad es la figura más completa para hacer negocios es que aquí en el Perú una de cada cinco personas utiliza la EIRL, mientras que el resto prefiere las sociedades en sus diversas modalidades. Tampoco pensamos que se deba eliminar la EIRL, es mejor dejar que sea el empresario quien decida.

Así, la delimitación de este tema, que ha sido muy tocado de modo doctrinario pero nunca analizado como en este libro, es el referido a la reforma societaria que significaría la existencia y regulación total de la unipersonalidad societaria en la Ley General de Sociedades peruana, y principalmente de dos maneras específicas: la constitución de sociedades unipersonales mediante la declaración de voluntad y no obligatoriamente bajo un contrato; y la posibilidad de la conversión de una sociedad plural que cae en soledad (independientemente de la razón) en una sociedad unipersonal, con el fin de evitar la extinción de pleno derecho que sanciona el artículo 4 de la Ley General de Sociedades.

Nuestra normatividad es muy estricta en lo que se refiere a la creación de una sociedad, y sobre todo a la condición de su existencia, por lo cual obliga y hasta castiga con la disolución cuando una de ellas cae, por cualquier circunstancia, en soledad. Esto, en nuestra opinión, es muy grave, pues afecta la continuidad en el mercado de las sociedades que no quieren salir de él, que tienen obligaciones, proveedores, personal a cargo, pero que por causas de las cuales no son culpables, son disueltas sin ninguna opción y en contra de su voluntad.

La unipersonalidad societaria es, desde la perspectiva jurídica doctrinaria del concepto de sociedad, una institución. No es únicamente (o necesariamente) un contrato, y mucho menos nace obligatoriamente de él, dado que puede hacerlo también de la declaración de voluntad. 
Y lo más anecdótico es que la normatividad peruana, a pesar de lo que se cree, sí permite la unipersonalidad societaria. Y no solo eso, la regula y es de obligatorio cumplimiento unipersonal para sociedades establecidas por ley. Siendo así, ¿por qué, entonces, la limitación al público y solo su permisibilidad a un grupo minoritario? ¿Por qué la sanción extrema de la disolución de pleno derecho en caso de unipersonalidad? No hay explicación, o por lo menos no hemos encontrado más que una reiterada y recalcitrante posición de que atenta contra el sentido lingüístico del término «sociedad».

Porque aquí se han enfrentado concepciones radicalmente opuestas. Principalmente en el tema lingüístico, no en el jurídico. Para algunos, la sociedad unipersonal (sea en su forma originaria o sobrevenida) es un cauce jurídico válido para las exigencias de la pequeña y la mediana empresa. Otros consideran la sociedad unipersonal (basados en concepto literal) como una situación impensable y ridícula, ilógica, pasando por llamarla «irregular», «anómala», «excepcional» (es decir, algo que nunca debe ser considerado como sociedad de capital), por carecer del requisito de la compañía (entiéndase dos personas), atentando contra el principio de ser social y violentando la etimología de la palabra «sociedad».

¿Pero es tan complicado entender que el concepto jurídico o la interpretación jurídica «sociedad» es totalmente diferente del concepto lingüístico? Estamos convencidos de que no, pero muchos no comparten esta posición. Dejemos de lado la perspectiva lineal de que la sociedad es solo un contrato, y veámosla como una institución.

Y mientras discutimos, los empresarios buscan «tecnicismos» y hasta «triquiñuelas» legales para poder cumplir con el requisito de la pluralidad de la ley. ¿Cómo lo hacen? Pues bajo la figura de un socio ficticio, un socio de favor. Ese testaferro que sirve solo para figurar simbólicamente como otro más, cuando la sociedad la controla uno solo. Resulta común una sociedad formada por un socio con $99 \%$ de acciones y otro con $1 \%$. Entonces, las preguntas son las siguientes: ¿esto es necesario? ¿No sería más fácil promover la autenticidad permitiendo la posibilidad legal a una persona de decidir si quiere constituir una sociedad en solitario, sin la colaboración de sus pares?

Como hemos comentado, actualmente no se permite que la sociedad continúe con un solo socio ante la pérdida de pluralidad, solo da la opción de que se pueda continuar con el desarrollo de la sociedad si logra encontrar otro socio. De tal manera, podemos concluir que la unipersonalidad societaria busca defender la libre voluntad del socio de poder optar por cualquier escenario, sea crear una sociedad solo o mantenerla en soledad, de ser el caso. 
Así lo establecía también la Exposición de Motivos de la Ley 2/1995, Ley de Sociedades de Responsabilidad Limitada de España: «[la] admisibilidad general de la sociedad unipersonal no es otra cosa sino un homenaje a la sinceridad de que todo legislador debe hacer gala cuando advierte un divorcio entre la realidad y el derecho legislado». Se hace evidente el deseo de poder contar con la posibilidad de realizar actividades comerciales de modo solitario.

Lo que se busca desarrollar en este libro es todo lo que significa entender la unipersonalidad societaria, en sus formas tanto originaria como sobrevenida, y sobre todo desterrar los mitos y dogmas clásicos que consideran un peligro a la sociedad unipersonal, como una puerta abierta a la comisión de delitos (pues se piensa que el socio único puede hacer con ella lo que le dé la gana) o una condición irregular y excepcional de las sociedades. Incluso, destierran la idea cuando ven el término «sociedad unipersonal», considerándolo una contradicción o un sinsentido, lo cual es totalmente incorrecto, pues así se le llama a la identificación legal de una persona jurídica que actúa en soledad en el ámbito comercial.

En este libro desarrollaremos desde la casuística, la doctrina, el derecho positivo y el derecho, en comparación con las experiencias de otros países, la importancia de la unipersonalidad societaria. Para empezar, en el capítulo 1 veremos los antecedentes y las nociones generales de la sociedad unipersonal, con algunos casos imaginarios (si el lector lo cree así) y los problemas de los empresarios.

En el capítulo 2 haremos un repaso de los antecedentes, la doctrina societaria, las tesis, las opiniones a favor y en contra de la sociedad unipersonal, sus características y sus clases, así como de su origen y su evolución. En suma, nos convenceremos de que no es la oveja negra del derecho societario que nos habían hecho creer, sino todo lo contrario: una figura innovadora y muy útil para el desarrollo económico del socio que desea realizar la aventura comercial en solitario.

En el capítulo 3 notaremos la posición de la legislación societaria peruana con relación a la sociedad unipersonal. Veremos que, a pesar de lo que se podría pensar, la unipersonalidad societaria sí está reconocida, existe, es válida y está regulada para ciertos agentes del mercado (como son las empresas que forma el Estado, las empresas subsidiarias del sistema financiero y el sistema de mercado de valores), pero limitada para todos los demás. Analizaremos también las experiencias en otros países, como Colombia, Inglaterra, Alemania, Francia y Estados Unidos. Y, por último, haremos un repaso de la Directiva 89/667/CEE de la Comunidad Económica Europea (CEE), que 
reguló la sociedad unipersonal en dicho continente; así como del reciente Proyecto de Directiva del Parlamento Europeo y del Consejo sobre las societas unius personae (SUP), del 9 de abril de 2014.

Por último, en el capítulo 4 desarrollaremos los aspectos jurídicos de la sociedad unipersonal, su constitución, organización, responsabilidades y relaciones jurídicas, así como las ventajas y las desventajas de esta figura.

Este libro es importante porque al final, junto con el lector, comprenderemos que gracias a la existencia y regulación de la unipersonalidad societaria, y en forma de una sociedad unipersonal dentro de la Ley General de Sociedades, se lograría una meta significativa, la cual sería dar un paso más en lo referido a la implementación de nuevas formas jurídicas para hacer negocio. Dejar de pensar únicamente en el término «sociedad» según la visión lingüística y comenzar a entender el concepto jurídico de la sociedad como una institución, independiente de su formación y de sus miembros.

Y, lo más importante, nos liberaríamos de los prejuicios que implica la creación de una sociedad por parte de una persona, y se garantizaría a cualquier empresario que por alguna razón quede solo en la aventura empresarial la posibilidad de continuar con la gestión de su empresa, no limitándolo a un plazo estricto, menos castigándolo con la disolución de pleno derecho, sino dándole la oportunidad de optar por la unipersonalidad hasta que, de ser el caso y siempre primando la libertad empresarial, decida si desea tener otros socios.

Por ello, la unipersonalidad societaria bajo la figura de la sociedad unipersonal es, en virtud a este trabajo, la evaluación doctrinaria y jurídica de un medio técnico, eficiente, real y práctico de propiciar la actividad comercial peruana, buscando garantizar eficiencia y bienestar, poniendo en el sistema societario peruano una nueva alternativa de negocios, sin tener que recurrir a tecnicismos o vacíos de la ley para lograr un desarrollo en solitario.

Este libro está dirigido al estudiante de derecho, al empresario, al abogado profesional, al público en general y a cualquiera que sea amante del derecho empresarial y corporativo y que desee conocer nuevos conceptos y teorías, así como explorar otras formas jurídicas de hacer negocio. Esperamos que quizá algún legislador reconozca la importancia de la unipersonalidad societaria, no abierta solo a algunas instituciones públicas o privadas, sino beneficiosa para todos los empresarios peruanos que estén interesados en optar por esta importante figura. 


\section{Capítulo 1. Análisis de la problemática en nuestra realidad societaria peruana}

\subsection{ANAlizando El PROBLEMA CASO POR CASO}

Antes de entrar en nuestro tema, nos hemos permitido hacer una simbología práctica en casos que aterrizaremos sobre la idea de lo que se va a desarrollar en este estudio, conforme hemos investigado y conocido durante la experiencia profesional. Después de hacer esta precisión, algo en broma y algo en serio, debemos advertirles que cualquier parecido con la realidad es pura y absoluta coincidencia ${ }^{1}$ :

\subsubsection{Caso 1. Sociedad por necesidad o por ser necesario}

Juan Pérez es una persona que tiene «ángel» para los negocios, pero, como muchos empresarios peruanos, no cuenta con el capital necesario para iniciar un negocio propio, y quiere empezar una nueva actividad comercial en el rubro de venta de computadoras. Su visión es convertirse en el largo plazo en uno de los más grandes empresarios peruanos en este rubro, no solo en el ámbito nacional sino, por qué no, también en el internacional. Su vecino Pedro Díaz labora en una empresa privada y gana un sueldo que le ha permitido contar con un ahorro importante en el banco, y después de tanto trabajar tiene la idea de invertirlo en un buen proyecto de negocios. Así que, cuando conoce de la idea de Juan, decide invertir poniendo en claro que él

1 Los casos a los que se hace referencia en este libro son en parte producto de la imaginación y creación propia del autor, pero también son parte de la realidad, tal como se verá más adelante. Estas historias se han basado en problemas, algunos sencillos y otros no tanto, que no pueden ser resueltos tan fácilmente como pareciera. La doctrina, la jurisprudencia societaria y demás efectos legales, en menor o mayor medida, podrían impedir su solución, por lo que son situaciones perfectamente plausibles. 
solamente se encarga de la inversión y no del desarrollo del negocio, es decir, no piensa hacer absolutamente nada.

Como son dos personas, la ley societaria permite que puedan ambos unir esfuerzos y convertirse en una sociedad para lograr sus objetivos comerciales. Esta historia sería de lo más común, pero, si hacemos un paréntesis y nos efectuamos las siguientes preguntas, las respuestas nos harán pensar en algo más allá:

- ¿Juan Pérez realmente quería asociarse con Pedro Díaz para realizar la actividad comercial de venta de computadoras que siempre soñó?

- ¿La actividad comercial que va a realizar Juan Pérez podría desarrollarse sin la ayuda que le brinda tan «desinteresadamente» Pedro Díaz?

Ante estas preguntas, la respuesta más rápida sería SÍ, aunque quizá la mejor debería ser DEPENDE. Dada nuestra regulación societaria, y teniendo en cuenta que todo el trabajo, el know how, así como la administración, es de Juan, consideramos que la respuesta tendría que ser NO. Pero, dado que Juan quiere realizar su negocio, tendría que hacerlo necesariamente con participación de otra persona. El tema del dinero es notoriamente discutible, dado que, si Juan lo tuviera, todo sería diferente.

No estamos en contra de decirle que forme una EIRL, pero el problema es que hay algo que desalienta a Juan, y es la forma como está redactado el texto del artículo 1 del D. L. 21621, que literalmente dice:

«Artículo 1ํ-. La Empresa Individual de Responsabilidad Limitada es una persona jurídica de derecho privado, constituida por voluntad unipersonal, con patrimonio propio distinto al de su Titular, que se constituye para el desarrollo exclusivo de actividades económicas de Pequeña Empresa, al amparo del Decreto Ley 21435» (Las negritas son nuestras)

Es decir, que la EIRL no le permitirá realizar actividades en gran escala, pues la norma es solo para «pequeñas empresas». Si la idea es que Juan quiere llegar a ser un empresario internacional con este tipo jurídico, no puede legalmente hacerlo. 


\subsubsection{Caso 2. Yo puedo solo... ipero no me dejan! ${ }^{2}$}

Bill Gates, magnate multimillonario ${ }^{3}$ de Microsoft, quiere realizar su actividad comercial en el Perú. Ingresará al mercado peruano en el rubro de computadoras. Pregunta: teniendo en consideración el potencial y las características particulares del señor Gates, ¿considera usted que necesitará socios en el Perú? Más aun: ¿necesitará recursos económicos? ¿Necesitará alianzas estratégicas? La respuesta, conociendo su patrimonio económico, es obviamente no. Entonces: ¿podrá competir, por ejemplo, con la sociedad formada de Juan y Pedro? La respuesta, aunque sea difícil de creer, también es NO. Es más, su multimillonario patrimonio en nuestro ordenamiento legal es solo personal y no importa, es irrelevante jurídicamente al momento de querer constituir una sociedad; por ello, no podría competir con Juan y Pedro del caso anterior, pues necesitaría la dualidad personal, además del capital. Requiere compañía para poder ser una sociedad, pudiendo solo actuar si lo deseara empresarialmente como cualquier persona natural, pero con la condición de que su responsabilidad sería ILIMITADA. Ser sociedad implica necesariamente la compañía obligatoria de otro socio. Y ese otro socio... ¡sí que se la llevaría fácil!

Punto adicional es que quiere hacerlo a través de su propia empresa, Microsoft. Aquí el lector dirá: pero que forme una EIRL. De nuevo, le recomendaría una lectura del artículo 1 de la Ley 21621 (pequeñas empresas, ¿recuerdan?), y otro punto menos para la EIRL es la imposibilidad de constituirla con personas jurídicas: solo se permite mediante personas naturales.

Otro lector, quizá más ducho en el ramo societario, daría esta respuesta: que constituya una EIRL como persona natural, donde sea el titular-gerente; luego, asociándose él mismo como persona natural, que se una para formar una sociedad y asunto arreglado. Buena respuesta, pero resulta engorroso y toma tiempo, además de que existe un pequeño detalle que quizá haya olvidado: los tributos que tendría que realizar al fisco se multiplicarían, al hacer esta figura, por cuatro, porque ahora tiene que declarar la renta de la sociedad, las rentas en su condición de socio de la sociedad,

2 Este caso es el inverso del anterior y está tomado del ejemplo utilizado por el doctor Enrique Vigil, profesor de Derecho Comercial en la USMP, que sustenta en forma más precisa la justificación lógica de no contar con un socio adicional cuando el socio fundador presenta todos los medios para poder ejercer la actividad comercial sin la necesidad de otro.

3 Según la lista Forbes de 2016, Bill Gates está en el primer lugar de los hombres con más dinero en el mundo, con un capital de 75,9 billones de dólares: http://www.forbes.com/profile/bill-gates/ 
las rentas por la EIRL y por último las rentas en su condición de ser titular-gerente ${ }^{4}$. Si fuera asesor legal, ¿lo recomendaría?

\subsubsection{Caso 3. Si tú no estás... ¡Oh...!, y ahora... ¿quién podrá ayudarme?5}

Ana y María son hermanas y desde muy pequeñas tenían la idea de hacer juntas un negocio de modas. Es por ello que, preparándose para el futuro, antes de morir sus padres ambas terminaron sus estudios. Ana estudió corte, confección y alta costura; mientras que, por su parte, María estudio marketing y administración de empresas. Estando solteras, sin hijos y sin compromisos, constituyeron una sociedad de responsabilidad limitada en 2003 en partes iguales. Gracias a su esfuerzo lograron en diez años de vida empresarial consolidarse como una de las mejores empresas peruanas, con más de cien trabajadores, múltiples clientes y reconocimiento en diversos eventos internacionales de moda. De ahí que decidieron tener una sucursal de la empresa en Francia y otra en el Perú. Ana se quedaría administrando la empresa en Lima, y María administraría la sucursal en Francia.

En uno de sus viajes fuera del país, Ana sufre un grave accidente y muere. ¿Podrá seguir operando esta sociedad? La respuesta más lógica es que María busque otra persona para continuar la sociedad.

Y así fue, pero, como la industria francesa era muy exigente, no pudo darse tiempo hasta después de un año. Durante ese tiempo, la sociedad en Lima seguía operando con su gerente general normalmente. Grande fue su sorpresa cuando quiso inscribir el nombramiento del nuevo socio en Registros Públicos declararon a su sociedad disuelta de pleno derecho, en aplicación del artículo 4 de la Ley General de Sociedades ${ }^{6}$.

4 Debemos hacer la precisión de lo indicado en el Informe 007-2015-SUNAT/5D0000 de fecha 12 de enero de 2015, donde la administración tributaria ha establecido, en el punto 2, que las «rentas generadas por el titular-gerente de una EIRL por la prestación de sus servicios como profesional independiente a favor de dicha EIRL, califican como rentas de quinta categoría».

5 Este caso está basado en lo resuelto por la Resolución 1295-2008-SUNARP-TR-L del 26 de noviembre de 2008. Apelante: Carlos José Carrizales Recio. Título: 468488 del 17 de julio de 2008. Recurso: HTD 54679 del 26 de agosto de 2008. Registro: Registro de Sociedades de Lima. Acto(s): Regularización de sociedad. Transferencia de participaciones. Nombramiento de gerente. Sumilla: Pérdida de pluralidad de socios. «La pérdida de la pluralidad de socios de una sociedad por más de seis meses constituye causal de disolución de pleno derecho; por tanto, no puede optar por regularizarse».

$6 \quad$ Ley 26887, Ley General de Sociedades. Artículo 4. Pluralidad de socios. La sociedad se constituye cuando menos por dos socios, que pueden ser personas naturales o jurídicas. Si la sociedad pierde la pluralidad mínima de socios y ella no se reconstituye en un plazo de seis meses, se disuelve de pleno derecho al término de ese plazo. No es exigible pluralidad de socios cuando el único socio es el Estado o en otros casos señalados expresamente por ley. 


\subsubsection{Caso 4. Yo soy el socio, pero no sé nada}

Julio y Martín son socios de una sociedad anónima dedicada al rubro textil desde hace más de cinco años. En ella, Julio solo participa cada vez que lo llama Martín, quien es gerente general y socio mayoritario, dado que el primero es solo un socio ficticio, es decir, un «socio de favor», y no tiene ningún tipo de participación en la sociedad. Aquí el experto y único dueño del negocio es Martín.

Un día, en una reunión habitual para firmar documentos de la sociedad, Martín le dice que esta aburrido de la sociedad y que, por lo tanto, dejará todo como está. Se lleva sus ganancias (que ya había recogido previamente) y deja a Julio solo. Si bien él podría manejar el negocio ante la abrupta salida de su socio (quien era el que dirigía la empresa), a pesar de que no conoce del mismo, no tendrá más salida que buscar otro socio, pues si no lo hace, en el plazo de seis meses la sociedad se disolvería de pleno derecho y él tendría que asumir ilimitadamente las deudas. ¿Podrá hacerlo? Cabe recalcar que la sociedad debe cumplir con sus obligaciones contractuales con sus clientes, a los cuales no les interesa quiénes sean los socios o si uno de ellos ya no está.

Y otra cosa más, dado que Martín era el socio mayoritario, todas las decisiones que pudiera realizar Julio son en minoría, por lo que no podrían inscribirse en el registro. Y dado también que Martín no ha dispuesto sus acciones, él sigue siendo socio. Y ahora....Oh..., ¿quién podrá ayudar a Julio?

\subsubsection{Caso 5. Todo estaba bien, pero llegaste tú}

Sandra y Victoria van a constituir una sociedad civil para dedicarse a la repostería y las dos (tienen pareja, pero están solteras) piensan dedicarse íntegramente a este negocio, que ya gracias a sus contactos y múltiples conocidos tiene varios pedidos importantes. Después de firmar la minuta de constitución y antes de hacerlo con la escritura pública, Victoria realiza un viaje al interior urgentemente por dos semanas y le dice a su amiga Sandra que la espere, y que cuando regrese firmará la escritura pública y empezarán el negocio formalmente.

En la semana en que Victoria estaba de viaje, Sandra, como gerente de la sociedad (aún no formalizada) firma tres contratos con unos clientes, para los cuales debe cumplir con las entregas de varios postres en tres semanas. Cuando regresa Victoria, resulta que no puede firmar la escritura pública, puesto que el viaje que realizó en 
forma urgente fue una sorpresa de su novio y no solo le pidió matrimonio, sino que incluso se casaron días después. Ante esto, Victoria dice que, al ser ahora casada, ya no puede firmar la escritura pública, y, más aun, que debe intervenir su esposo, algo con lo que Sandra no está de acuerdo, puesto que esa no era la idea que habían tenido cuando decidieron empezar el negocio. ¿Qué va a pasar con los contratos? ¿Podría hacerlo Sandra sola y sin ayuda? ¿Podrá Sandra encontrar una nueva socia como su amiga Victoria?7

\subsubsection{Caso 6. No me gustas, no te quiero, no te amo... pero te necesito ${ }^{8}$}

Antonio, Camila y Andrea son hermanos y socios de una sociedad de responsabilidad limitada, y desde hace algún tiempo están teniendo problemas debido a que Antonio y Camila, cuando Andrea está buscando nuevos clientes, se apropian de los ingresos de la sociedad en gustos y temas personales, puesto que, como Andrea es la socia con mayor participación en la sociedad, sus utilidades son mucho mayores que las de sus hermanos. Ante este problema, Andrea ha decidido excluirlos a ambos y seguir sola en la sociedad. Para hacerlo debe convocar a ambos a una asamblea, conforme a lo dispuesto en el artículo $293^{9}$ de la Ley General de Sociedades, y decirles que se retiren. Fácil, ¿no?

$7 \quad$ La condición de irregularidad en la Ley General de Sociedades se ha definido en el artículo 423 en dos formas; la primera, en la cual se hace referencia a las sociedades irregulares de hecho, aquellas que no se han constituido o inscrito conforme a ley o que actúan en forma como una sociedad sin haberse constituido o inscrito; y las sociedades irregulares de derecho, las cuales solo tienen celebrado el pacto social. Este caso hace referencia a una irregularidad de derecho.

8 Mediante la Resolución del Presidente del Tribunal Registral 099-2009-SUNARP/PT, de fecha 1 de junio de 2009, se dispuso la publicación del precedente registral de observancia obligatoria, aprobado en la sesión del Cuadragésimo Octavo Pleno del Tribunal Registral de la Superintendencia Nacional de Registros Públicos (Sunarp), realizado el 21 de mayo de 2009, según el cual «el socio de la sociedad comercial de responsabilidad limitada cuya exclusión se pretende debe ser convocado a la junta general en la que se debatirá su exclusión». Se agrega que «para el cómputo de la mayoría en el acuerdo de exclusión del socio de una sociedad comercial de responsabilidad limitada no se tendrá en cuenta las participaciones del referido socio», criterio sustentado en la Resolución 710-2009-SUNARP-TR-L de fecha 22 de mayo de 2009.

9 El artículo 293 de la Ley General de Sociedades aborda la exclusión del socio en la sociedad comercial de responsabilidad limitada en los siguientes términos:

«Artículo 293.- Exclusión y separación de los socios

Puede ser excluido el socio gerente que infrinja las disposiciones del estatuto, cometa actos dolosos contra la sociedad o se dedique por cuenta propia o ajena al mismo género de negocios que constituye el objeto social. La exclusión del socio se acuerda con el voto favorable de la mayoría de las participaciones sociales, sin considerar las del socio cuya exclusión se discute, debe constar en escritura pública y se inscribe en el Registro.

Dentro de los 15 días desde que la exclusión se comunicó al socio excluido, puede este formular oposición mediante demanda en proceso abreviado.

Si la sociedad solo tiene dos socios, la exclusión de uno de ellos solo puede ser resuelta por el juez, mediante demanda en proceso abreviado. Si se declara fundada la exclusión se aplica lo dispuesto en la primera parte del artículo 4.

Todo socio puede separarse de la sociedad en los casos previstos en la ley y en el estatuto». 
Todos estos casos, según nuestra opinión luego de la investigación realizada, podrían haber sido resueltos con la existencia y regulación de la sociedad unipersonal (S. U.) en nuestro derecho societario.

Quizá el lector podrá pensar que algunos de los casos expuestos resultan excesivos, increíbles y hasta carecen de toda lógica. Sin embargo, como profesionales del derecho, sabemos que en nuestra vida diaria son algo común, fácil de encontrar, y las consecuencias de la ley, que son imperativas conforme nuestra normatividad, difícilmente pueden resolverlas como esperan nuestros clientes.

¿Pero qué es la unipersonalidad societaria? En sencillo, para después ahondar más en el tema: la unipersonalidad societaria es aquella persona natural que en soledad constituye (lo que se le llama «unipersonalidad originaria»), por la voluntad de un único socio o fundador, una sociedad, en la cual este asume todas las acciones y/o participaciones al momento de crearla.

También se le llama «unipersonalidad societaria» al momento en el cual todos los socios de una sociedad pluripersonal deciden otorgar, entregar o hacer recaer la totalidad de las acciones y/o participaciones de la sociedad en un solo socio único (lo que se llama «unipersonalidad sobrevenida»). También puede darse cuando, por causas imprevistas, la titularidad de las acciones o de las participaciones de varios pasa a poder de una sola persona.

Es por ello que cuando hablamos de unipersonalidad societaria, la forma jurídica que adquiere es la sociedad unipersonal.

Así, el fenómeno de la unipersonalidad societaria no debe considerarse como un régimen especial, excepcional, un imposible jurídico castigado con la disolución de pleno derecho (como ha sido establecido en la Ley General de Sociedades ${ }^{10}$ y que jamás debe producirse), sino actual y necesario para resolver problemas reales y posibles, tal y como hemos expuesto en los casos antes mencionados. El hecho de incluir la figura de la sociedad unipersonal (o, por su abreviatura, la S. U.) dentro del sistema normativo societario no desencadenaría el cambio de denominación de la norma o la creación de nuevas legislaciones mercantiles o «Ley de la Sociedad Unipersonal», por dar un ejemplo.

El sentido de este trabajo será, entonces, desarrollar las posibilidades sobre esta no tan antigua e importante figura jurídica, cuyo uso existe desde hace mucho

10 El artículo 4 de la Ley General de Sociedades prevé la disolución de pleno de derecho de sociedades, al perder la pluralidad de socios. 
tiempo. A la vez, devastar dogmas jurídicos, apostando por un desarrollo pragmático y moderno del tema, conociendo y entendiendo que su utilización sería muy útil en la normatividad societaria. De esa forma tendremos una nueva opción empresarial de hacer negocio, mejorando la actividad comercial en el Perú.

\subsection{FUNDAMENTO CONSTITUCIONAL DE LA UNIPERSONALIDAD SOCIETARIA}

En nuestra Constitución Política de 1993 se consagró el pluralismo económico como un derecho constitucional fundamental ${ }^{11}$. Esto implica la libertad o facultad autónoma de las personas para unir sus fuerzas y/o recursos, en aras de impulsar conjuntamente la realización de propósitos o finalidades comunes mediante la adopción, para el efecto, de distintas formas asociativas.

Esto, sumado a la libertad de contratar ${ }^{12}$, busca la creación de entes jurídicos distintos para todas las personas naturales con capacidad para ejercer derechos y de contraer obligaciones, para lograr la satisfacción de un interés u objetivo de lucro. Desde esta perspectiva, corresponde el legítimo derecho de toda persona de utilizar todas las formas jurídicas que le permitan realizar actividades económicas, sea en comunidad o en solitario.

El artículo $59^{13}$ de la Constitución Política del Perú estipula al inicio de su texto que el «Estado estimula la creación de riqueza y garantiza la libertad de trabajo y la libertad de empresa». Este derecho o libertad se funda en la posibilidad jurídica de la creación de la actividad, y no necesariamente en comunidad, sino también en solitario,

11 Constitución Política del Estado Peruano. «Artículo 60.- Pluralismo Económico. El Estado reconoce el pluralismo económico. La economía nacional se sustenta en la coexistencia de diversas formas de propiedad y de empresa. Sólo autorizado por ley expresa, el Estado puede realizar subsidiariamente actividad empresarial, directa o indirecta, por razón de alto interés público o de manifiesta conveniencia nacional. La actividad empresarial, pública o no pública, recibe el mismo tratamiento legal».

12 Constitución Política del Estado Peruano. «Artículo 62.- Libertad de contratar. La libertad de contratar garantiza que las partes pueden pactar válidamente según las normas vigentes al tiempo del contrato. Los términos contractuales no pueden ser modificados por leyes u otras disposiciones de cualquier clase. Los conflictos derivados de la relación contractual sólo se solucionan en la vía arbitral o en la judicial, según los mecanismos de protección previstos en el contrato o contemplados en la ley.

Mediante contratos-ley, el Estado puede establecer garantías y otorgar seguridades. No pueden ser modificados legislativamente, sin perjuicio de la protección a que se refiere el párrafo precedente».

13 Constitución Política del Estado Peruano. «Artículo 59.- Rol Económico del Estado. El Estado estimula la creación de riqueza y garantiza la libertad de trabajo y la libertad de empresa, comercio e industria. El ejercicio de estas libertades no debe ser lesivo a la moral, ni a la salud, ni a la seguridad pública. El Estado brinda oportunidades de superación a los sectores que sufren cualquier desigualdad; en tal sentido, promueve las pequeñas empresas en todas sus modalidades». 
puesto que se busca poder desarrollar la actividad comercial libremente, solo o con otros, con los beneficios de separación de patrimonio y responsabilidad limitada.

Tal y como señalaba Marcial Rubio Correa (1999, p. 228) en sus comentarios, explicando sobre el artículo 59, se establecen varios deberes para el Estado en materia económica referidos a la libertad de empresa, los cuales han sido desarrollados por el Tribunal Constitucional $(2006)^{14}$ :

- Estimulación de la riqueza, entendida como uno de los objetivos centrales del Estado en materia económica.

- Libertad de trabajo, en sus dos dimensiones: libertad de elegir el trabajo y el derecho y el deber de trabajar.

- Libertad de empresa, comercio e industria. Libertad de empresa implica dentro de la vida empresarial la posibilidad de manejarse libremente, realizar actividades económicas, en el sentido de libre fundación de empresas y concurrencia al mercado, dentro del marco de la Constitución y la ley. Es el derecho de tomar decisiones libremente sin ofender al Estado. Libertad de comercio tiene que ver con la circulación de bienes y servicios e inclusivo de dinero y con llevar a cabo una actividad ligada al intercambio de mercaderías o servicios para satisfacer la demanda de los consumidores y usuarios. Y en cuanto a la libertad de industria, se refiere a la producción de los bienes. Se manifiesta en la libertad de elegir y obrar, según la propia determinación, en el ámbito de la actividad económica, cuyo objeto es la realización de un conjunto de operaciones para la obtención y/o transformación de varios productos (p. 426).

Para Echaiz y Moreno (2010), la libertad de empresa ha sido tradicionalmente obviada por el derecho peruano, pues no ha ofrecido materia de estudio para la doctrina ni la legislación, pero sí para la jurisprudencia.

Dentro de lo poco que menciona el Tribunal Constitucional ${ }^{15}$ como libertad de empresa, indica lo siguiente:

14 Expediente 3330-2014-AA, 11/07/05, P, FJ13 contenido en el libro La Constitución en la jurisprudencia del Tribunal Constitucional (2006). Sentencias vinculadas a los artículos de la Constitución. Gaceta Jurídica. Lima, Perú: 423.

15 Exp. 008-2003-AI/TC del 11 de noviembre de 2003. Se señala no solo la definición de libertad de empresa, sino también la de industria y la de comercio. 
«Se define como la facultad de poder elegir la organización y efectuar el desarrollo de una unidad de producción de bienes o prestación de servicios, para satisfacer la demanda de consumidores y usuarios». Más adelante añade: «Consecuentemente, dicha libertad debe ser ejercida con sujeción a la ley, siendo sus limitaciones básicas aquellas que se derivan de la seguridad, la higiene, la moralidad o la preservación del medio ambiente, y su ejercicio deberá respetar los diversos derechos de carácter socio económico que la Constitución reconoce» (Tribunal Constitucional, 2003).

Según Rubio (1999), comentando a Gerardo Ruiz y Rico Ruiz:

«El reconocimiento de la libertad de empresa, y la obligación de proteger su ejercicio por los poderes públicos, según el segundo párrafo del artículo 38, presupone la necesidad de una acción específicamente dirigida a la defensa de dichos objetivos constitucionales» (pp. 228-229).

Y continúa: «el artículo 38 reúne dos aspectos complementarios de la libertad de empresa: aquel que la reconoce como un ámbito de autonomía del individuo y aquel que se refiere a sus aspectos institucionales. A través del primero se confiere a cada ciudadano un derecho de libertad, dotado de un núcleo que ni el legislador puede tocar y directamente reclamable mediante acción ante los tribunales. En su segunda acepción, la libertad de empresa es reconocida en su dimensión institucional, es decir, como el marco objetivo en el que se garantiza el ejercicio autónomo del derecho individual» (Rubio, 1999, 228-229).

Es conocida la relación entre el Estado y la economía, la cual se ha manifestado a través de tres modelos económicos: la economía planificada (en un extremo), el libre mercado (en el otro extremo) y la económica social de mercado (entre ambos) ${ }^{16}$. La economía social de mercado es nuestro modelo a seguir.

16 Cada uno de estos modelos es totalmente diferente de los otros. El modelo de la economía planificada ve al Estado como un interventor, tanto así que solo él y nadie más que él conoce lo que requiere el mercado, pudiendo así determinar los precios de los productos. En el modelo del libre mercado no se ve al Estado, es más, no se le quiere ver, aplicando la máxima francesa laissez faire, laissez passer (dejar hacer, dejar pasar). Finalmente, el modelo de economía social de mercado sí ve al Estado, pero no como un interventor, sino como un arbitrio que regula las conductas empresariales, propiciando la competencia para conseguir una economía con rostro humano. 
Específicamente y con respecto a la economía social de mercado que nos ocupa, el Tribunal Constitucional (2006) ha indicado lo siguiente:

«En una economía social de mercado, tanto los particulares como el Estado asumen deberes específicos; en el primer caso, el deber de ejercitar las referidas libertades económicas con responsabilidad social, mientras que, en el segundo, el deber de ejercer un rol vigilante, garantista y corrector, ante las deficiencias y fallos del mercado, y la actuación de los particulares. En efecto, la Constitución reserva al Estado, respecto del mercado, una función supervisora y correctiva o reguladora, en el entendido que, si bien el ejercicio de la libertad de los individuos en el mercado debe ser garantizada plenamente, también es cierto que debe existir un Estado que, aunque subsidiario en la sustancia, mantenga su función garantizadora y heterocompositiva» ${ }^{17}$ (Fundamentos 6 y 7).

En términos más generales, la libertad económica se ha liberado de toda forma de intervención del Estado, limitándose este a un aspecto subsidiario en la economía.

Dentro de los derechos de libertad de empresa y de contratar, es posible que cualquier persona, sea natural o jurídica, pueda, con las limitaciones de la ley, optar por cualquier tipo de forma jurídica que sea necesaria para realizar un negocio, y de la misma forma el Estado no debe bajo ninguna circunstancia impedir la continuación de una actividad comercial o un negocio que genera riqueza.

Así, estamos claros en que la libertad económica no es un derecho absoluto, pues es el mismo constituyente quien permite que el legislador le imponga límites para realizar fines constitucionalmente válidos ${ }^{18}$. Por ello, es legítimo que el legislador promulgue normas que limiten el ejercicio de esa libertad y al mismo tiempo faciliten la libertad de empresa ${ }^{19}$, siempre de manera compatible con el sistema de valores,

17 Obtenido de la Resolución 01963-2005-PA/TC del 5 de diciembre de 2006. Ver http://www.tc.gob.pe/ jurisprudencia/2007/01963-2006-AA.html

18 Dentro de este razonamiento se establece que los derechos (libertad de empresa, de industria o de comercio) no son absolutos y menos personalísimos; por tanto, ejercerlos supone el respeto a los principios y valores que la Constitución ha consagrado. Exp. 3330-2004-AA/TC del 11 de julio de 2005 (Calle Ocho contra la MML). De la misma forma, la sentencia contenida en el Exp. 4637-2006-PA/TC del 18 de abril de 2007 (Transportes Palomino «Buses-Camión» contra el MTC) indicó que la libertad de empresa no viola el objeto social de una empresa, sino que busca, en aras de una seguridad colectiva pública, evitar abusos en el ejercicio de la actividad comercial.

19 El Tribunal Constitucional, mediante sentencia de fecha 11 de noviembre de 2003, ha indicado que la libertad de empresa da «la facultad de poder elegir la organización y efectuar el desarrollo de una unidad de 
principios y derechos consagrados en nuestra Carta Magna, es decir, la posibilidad de utilizar formas jurídicas societarias que buscan agilizar el desarrollo de la riqueza en nuestro país ${ }^{20}$.

En conclusión, como comentan Echaiz y Moreno (2010) en su artículo:

«La Libertad de Empresa en la Jurisprudencia del Tribunal Constitucional [manifiesta que] el principio constitucional económico de la libertad de empresa ha sido atendido en el Perú por la Jurisprudencia del Tribunal Constitucional, la cual ha dejado en claro que, por un lado, puede tener condicionamientos (como ocurre en la mayoría de los supuestos, en referencia a los requisitos legales) y por otro también tiene límites (en tanto la autonomía de la voluntad) -sustentada en el interés individual- no es irrestricta, al tener como frontera el orden público» (p. 90).

Luego de estos considerandos y proposiciones jurídicas, no existe o se ha realizado ninguna objeción que permita intuir alguna negación o imposibilidad para la existencia de una actividad unipersonal, dado que ya existe la EIRL; por ello, haciendo una interpretación más amplia, tampoco impedimento para la institución de una sociedad unipersonal (S. U.) en el Perú. No hay nada que pueda impedir que una persona natural o jurídica, si desea, inicie su actividad comercial sin la participación de otra. Recordemos que no se trata aquí de un deseo egoísta, sino de una necesidad evidente.

Y de la misma forma, si se permite la creación de una persona jurídica unipersonal, por qué no permitir que una sociedad plural (entiéndase la creada por dos personas) pueda, de ser necesario o por las razones que sean, pasar a ser una sociedad unipersonal y seguir operando en el mercado. La sociedad unipersonal es una realidad evidente que, como veremos más adelante, no solo existe en la realidad peruana, sino que está debidamente regulada.

producción de bienes o prestación de servicios, para satisfacer la demanda de los consumidores o usuarios [...]. Consecuentemente dicha libertad debe ser ejercida con sujeción a la ley, siendo sus limitaciones básicas aquellas que se deriven de la seguridad, la higiene, la moralidad o la preservación del medio ambiente y su ejercicio deberá respetar los diversos derechos de carácter socio económico que la Constitución reconoce». Ver http://www.tc.gob.pe/jurisprudencia/2003/00008-2003-AI.html

20 Son varias las resoluciones del Tribunal Constitucional que buscan adecuar e interpretar debidamente los derechos que corresponden a los ciudadanos, pues muchos de ellos, enarbolando el derecho a la libertad de empresa, afectan derechos de terceros. Ver Exp. 3048-2007-PA/TC del 9 de noviembre de 2007, Exp. 1972-2007-AA/TC del 16 de noviembre de 2007, Exp. 2576-2008-PC/TC del 6 de octubre de 2008 y Exp. 4466-2007-PA/TC del 18 de marzo de 2009. 
Para poder revisar todo el contenido de esta edición, visite nuestra tienda virtual.

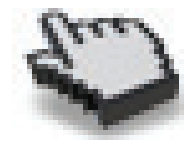

$\boldsymbol{\varphi}$

E MILIO FIGUEROA REINOSO

La sociedad unipersonal

La importancia de su regulación en el derecho societario

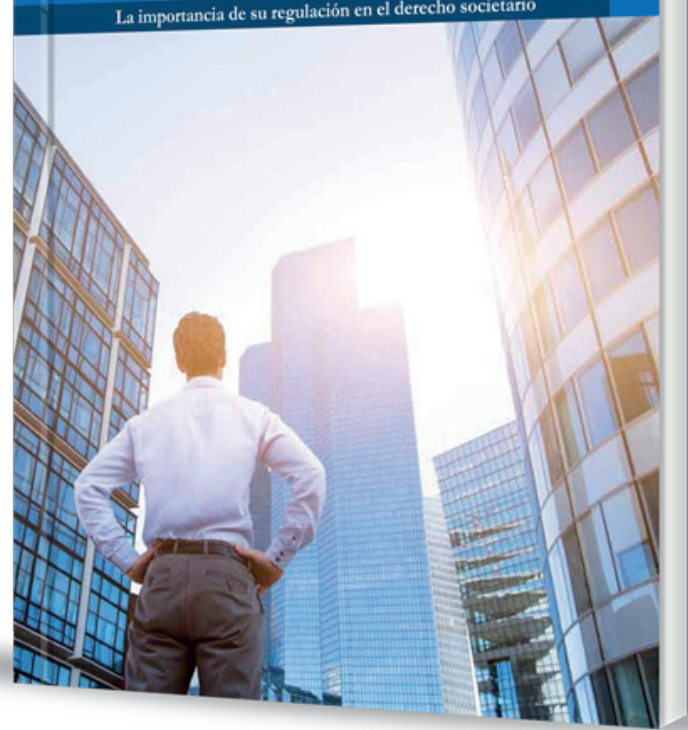

